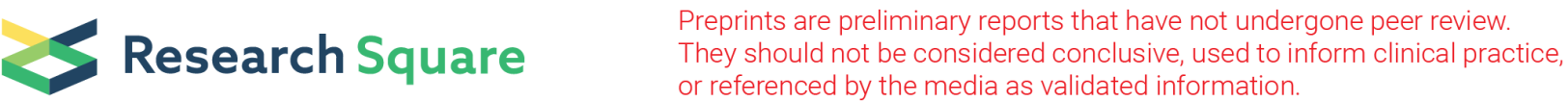

\section{The study of court-ordered forensic psychiatric evaluations for offenders with schizophrenia with homicide charges in Taiwan}

Hui-Yi Wang

Taipei Tzu Chi Hospital

Yu-Ching Chou

National Defense University

Hsin-An Chang

Tri-Service General Hospital

Yu-Cheng Kao

Tri-Service General Hospital Songshan Branch

Hui-Wen Yeh

Tri-Service General Hospital

Chin-Bin Yeh

Tri-Service General Hospital

San-Yuan Huang

Tri-Service General Hospital

Wei-Shan Chiang

Tri-Service General Hospital

Li-Yao Tang

Taipei Tzu Chi Hospital

Nian-Sheng Tzeng ( $\nabla$ pierrens@mail.ndmctsgh.edu.tw)

Tri-Service General Hospital https://orcid.org/0000-0001-5881-7089

\section{Research article}

Keywords: forensic psychiatric evaluation, schizophrenia, insanity defense, homicide charges, Taiwan, criminal court, felony

Posted Date: April 16th, 2020

DOI: https://doi.org/10.21203/rs.2.11545/v2

License: (a) (i) This work is licensed under a Creative Commons Attribution 4.0 International License.

Read Full License 


\section{Abstract}

Background: Homicidal offenders with schizophrenia who went through psychiatric evaluations are a small but significant group during criminal appeal. However, studies regarding the criminal responsibilities of homicide offenders with specific psychiatric diagnosis such as schizophrenia were rare. Our aims are to explore as to whether the types of crime, such as homicide or not would be related to the verdicts for the alleged offenders with schizophrenia in Taiwan, since our hypothesis was that homicide cases, rather than other alleged offenses, would be more likely to be regarded as no responsibility (legal insanity) or diminished responsibility for those defendants, in the forensic psychiatric evaluation opinions or the court verdicts.

Methods: A retrospective comparison of the homicide offenders with the non-homicide offenders with schizophrenia, registered between December 2000 and November 2009, was conducted in the web-based, national, open access court verdicts databank.

Results: There were $33(3.4 \%)$ in 9,691 criminal homicide offenders that had a diagnosis of schizophrenia. There were 33 in the homicide group and 22 in the non-homicide group. Among these defendants in the homicide group, three (9.09\%) were regarded as legal insanity, and $21(63.64 \%)$ were regarded as diminished responsibility, in comparison to the zero (0\%) as legal insanity and nine $(40.91 \%)$ as diminished responsibility in the non-homicide group $(p=0.029)$. In addition, the group with multiple evaluations tended to receive forensic psychiatric opinions as legal insanity ( $N=3 ; 33.33 \%)$, and the group with single evaluation tended to receive forensic psychiatric opinions as diminished responsibility ( $\mathrm{N}=16$; $66.67 \%)(p=0.017)$. The group with multiple evaluations tended to be ruled as legal insanity in the court $(p=0.001)$.

Conclusions: Homicide cases would be more likely to be regarded as legal insanity or diminished responsibility for the defendants with schizophrenia, in the forensic psychiatric evaluation opinions or the court verdicts.

\section{Background}

Homicides are one of the more serious crimes that are frequently referred for psychiatric evaluations and treatments (Cochrane, Grisso, \& Frederick, 2001). The rates of homicides offenders with schizophrenia varies, but were generally small: only $5-6.5 \%$ of all homicides were committed by people with schizophrenia (Golenkov, Large, Nielssen, \& Tsymbalova, 2011; Large, Smith, \& Nielssen, 2009; Meehan et al., 2006). However, homicide charges have predominated all the other charges: $53.33 \%$ of schizophrenic criminal offenders were charged with homicide in Taiwan (Yu et al., 2005). Regarding the rates of committing homicide, patients with schizophrenia were higher than the general populations. Studies showed a 6.5 to 8 -fold increase (Eronen, Tiihonen, \& Hakola, 1996), and an odds ratios of 5.85 to 18.38 (Schanda et al., 2004) in men and women, respectively. 
Patients with schizophrenia who were charged with homicides were more likely to be associated with substance use disorders, auditory hallucinations, delusional beliefs, previous history of violence, and family history of crimes, in comparison to those with non-homicide charges (El-Hadidy, 2012), and the same group tended to be under the influence of substances at the time of the offense (Eronen et al., 1996; Golenkov et al., 2011). One Australian population cohort suggested that the risk of committing a homicide were nearly 28 times more in patients with schizophrenia comorbid with substance use disorder than in the general population (Mullen, Burgess, Wallace, Palmer, \& Ruschena, 2000). Most of the time, the victims were the families from private residences (Joyal, Putkonen, Paavola, \& Tiihonen, 2004). The recidivism rate was high (Golenkov, Nielssen, \& Large, 2014), and up to the $44 \%$ of schizophrenic homicide offenders were determined legally insane (Packer, 1987).

In Taiwan, most forensic psychiatric evaluations were either court-appointed or prosecutor-appointed before the indictment. Criminal responsibilities were frequently asked by the court, but only the court could decide as to whether the forensic evaluations, therefore, the forensic evaluation opinions were just evidence regarding the defendants' criminal responsibilities. The evaluations were often done in a hospital. A team composed of two board-certified psychiatrists, or sometimes a senior psychiatric resident under the supervision of a board-certified psychiatrist, often teamed by one clinical psychologist, are appointed by the courts to perform psychiatric diagnostic interviews, mental and physical examinations, psychological assessments, routine laboratory work-ups, and sometimes, brain imaging studies (Kuo, 1983). The forensic psychiatric evaluations often included the mandatory treatment of those defendants who lacked or had diminished criminal responsibilities, nonetheless, the final verdict on the need for mandatory treatment are only made by the judges (H. Ho, Tsuang, Lin, \& Rin, 1997; Rin, 1976 ; Su, Yu, Yang, Tsai, \& Chen, 2000; W. C. Tsai, H. Rin, \& S. N. Lin, 1996; Tzeng et al., 2016; Wang et al., 2018; Yu et al., 2005). Most of the mandatory treatments are provided by the general hospitals with psychiatric services, mental hospitals, and psychiatric clinics, in addition, these facilities are contracted to provide scheduled visits or hospitalizations to the offenders, with the court or prosecutors' offices rulings (Chien et al., 2017; Wu et al., 2017; S. L. Yang, Tsai, \& Jang, 2008), instead of government-sponsored, professional forensic mental hospitals.

Studies regarding the criminal responsibilities of homicide offenders with specific psychiatric diagnosis such as schizophrenia were rare. We hypothesize that homicide cases, rather than other alleged offenses, would be more likely to be regarded as no responsibility or diminished responsibility for the defendants with schizophrenia, in the forensic psychiatric evaluation opinions or the court verdicts. Therefore, this study aims to compare criminal responsibilities, as well as further clinical management, between homicide and non-homicide schizophrenic offenders.

\section{Methods}

Study design 
This retrospective study was conducted to test the hypothesis as to whether the homicide cases, rather than other alleged offenses, would be more likely to be regarded as no responsibility or diminished responsibility for the defendants with schizophrenia, in the forensic psychiatric evaluation opinions or the court verdicts.

\section{Data sources}

Full copies of the court verdicts were obtained by reviewing the publicly available judicial decision documents retrieved from the document-bank set up and maintained by the Judicial Yuan in Taiwan from 2000 to 2009. A computerized screening was used to search for the criminal verdicts with the keywords "schizophrenia plus forensic psychiatric evaluation", with or without homicides. The reviewing of each verdict was conducted by two forensic psychiatrists, one neurologist, and one clinical psychologist from the authors. The purpose was to look for criminals with schizophrenia and also those with the results of the forensic evaluations mentioned in the verdict. There were 55 defendants with schizophrenia confirmed by the researchers, who had received the psychiatric evaluations, from the 4,484 verdicts in the database. The same case that went through multiple evaluations during the appeal process or mentioned in different verdicts could easily be noted though the system and calculated as one single data. A computerized screening was used to search for the criminal verdicts with the keywords "homicides" from December 2000, to November 2009, and 9,691 hits were found.

\section{Definitions of terms}

In Taiwan, the misdemeanor, or non-felony crimes, are those with a sentence of less than three years, including burglary, injury, and chemical abuse, and the felony are crimes with a sentence of more than three years, including murder, serious harm, robbery, rape, and aggravated assaults (L. C. J. Ho, Wu, \& Huang, 2010).

Furthermore, forensic experts are free to express their opinions about the ultimate issue, the criminal responsibility at the offense, according to their expertise, as aforementioned. However, judges hold the final decision on the ultimate issue. The court accept the forensic psychiatric opinions, while the judge's final decision is concord with the forensic psychiatric opinions(H. Ho et al., 1997; T. W. Yang, Yu, \& Pan, 2017; Yeh et al., 2019; Yu et al., 2005).

\section{Ethical approval}

This study was conducted in accordance with The Code of Ethics of the World Medical Association (Declaration of Helsinki). The Institute Review Board of the Tri-Service General Hospital approved this 
study (No. 2-102-05-044).

\section{Measurements}

All individuals included in the study were identified as patients with schizophrenia, using the DSM-IV-TR criteria, as well as other comorbid psychiatric disorders on the written sentence databank (American Psychiatric Association, 2004). A full forensic psychiatric examination in Taiwan often includes psychiatric interviews, physical and neurologic examinations, mental status and psychological evaluations, electroencephalographic (EEG) studies, and, if indicated, neuro-imaging tests.

\section{Statistical analysis}

All the schizophrenic criminal offenders were categorized according to type of offences as those with homicide charges and those with non-homicide ones. (Table 1) Among those with homicide charges, there were people committed and those who attempted homicide as well as those who went through repeated evaluations and those who had single evaluation. We further categorized them (Table 2 and 3 ). The groups were compared and tested for significant differences in gender, diagnosis, forensic psychiatric opinions, the latest court decision on legal responsibility, hospitals for the forensic psychiatric evaluations, the judges' acceptance of the forensic psychiatrists' opinions on legal responsibility, and further treatment or correction after the penalty, were made using the chi-square test and the Fisher's exact test. Also, during the analysis, we divided our cases by the times of evaluation, with the statistical significance set at $p<0.05$.

\section{Results}

There were 33 in the homicide group and 22 in non-homicide group, and 33 (3.4\%) in 9,691 criminal homicide offenders had a diagnosis of schizophrenia. In the homicide group, nine were charged as attempted homicide. Demographic data as well as other characteristics during the legal appeal are as listed on Table 1. Males were predominant in both groups. The crimes committed were mostly felony in the non-homicide groups. Among all the subjects, about $30 \%$ were recorded with comorbidities, which were substance use disorder (18.18\% for both groups), organic mental disorder, or a history of traumatic brain injury (6.06\% and $4.55 \%$ for the homicide and non-homicide groups). Two were comorbid with antisocial personality disorder in the homicide groups. Three cases were evaluated not only for their insanity plea, but also for their competency to stand trial.

Among these defendants, $27.27 \%$ in the homicide group and $59.09 \%$ in the non-homicide group were ruled as being criminally responsible, while $63.64 \%$ in the homicide group and $40.91 \%$ in the nonhomicide group were sentenced with diminished responsibility. In the homicide group, only $9.09 \%$ was regarded as legal insanity in forensic psychiatric reports opinions. In this study, the judges accepted most 
of the expert opinions:93.94\% in the homicide group and $86.36 \%$ in the non-homicide group. In addition, $27.27 \%$ in the homicide group and $9.09 \%$ in the non-homicide group received multiple ( $\geqq 2$ ) evaluations. Most of forensic psychiatric evaluations were performed in regional hospitals. In the court verdict, 9.09\% of the homicide group was considered as no responsibility (legal insanity) and $63.64 \%$ of the homicide group was considered as diminished responsibility. None of the non-homicide group was regarded as no responsibility and $40.91 \%$ was considered as diminished responsibility. The difference between these groups is significant $(p=0.029)$. In the court verdicts, $48.48 \%$ in the homicide group and $18.18 \%$ of the non-homicide group, were sentenced to receive the mandatory treatment, and the difference is statistically significant $(p=0.014)$. (Table 1$)$.

For those who committed and attempted homicide, there were no significances found for all the characteristics mentioned above (Table 2).

Those who received multiple evaluations (9 out of 33 schizophrenic homicide defendants) showed distinct characters: more cases with psychiatric opinions as no responsibility or diminished responsibility were noted $(p<0.001)$, and there was a trend toward receiving a sentence of no responsibility for their crime for the group that went through repeated examinations $(p=0.017)$ (Table 3$)$.

\section{Discussion}

This study is the first to analyze the characters of the forensic psychiatric evaluated defendants with a diagnosis of schizophrenia in Taiwan from a web-based, open-accessed court sentences databank. As aforementioned, the courts frequently request the psychiatrists' opinions on the criminal responsibilities and treatments for the offenders. Similar to several previous reports documenting the concordance between the insanity defenses and the professional opinions (H. Ho et al., 1997; T. W. Yang et al., 2017; Yu et al., 2005), the present study also found a high concordance rate between the forensic psychiatric opinions and the court verdicts.

Psychotic disorders are associated with criminal acts such as violence or homicides(Arseneault, Moffitt, Caspi, Taylor, \& Silva, 2000; Brennan, Mednick, \& Hodgins, 2000; Eronen et al., 1996; Schanda et al., 2004). Evolving diagnostic criteria, comorbid substance use, or antisocial personality trait, and being charged with illegal weapon possession, might greatly influence the processes and results of an insanity plea and forensic evaluations (Eronen et al., 1996). In our study, $60 \%$ of the schizophrenic criminal offenders were charged with major crimes of homicide, which is consistent with previous report (Yu et al., 2005).In the present study, 33 (3.4\%) in 9,691 criminal homicide offenders had a diagnosis of schizophrenia, which is close to the findings in the previous reports being 5\%-6.5\%(Golenkov et al., 2011; Large et al., 2009; Meehan et al., 2006).

The reports varied regarding the relationship between the criminal charges and the professional opinions on insanity defense or competency to stand trial (Nicholson \& Kugler, 1991; Rosenfeld \& Ritchie, 1998; Steadman \& Hartstone, 1983; Warren, Rosenfeld, Fitch, \& Hawk, 1997). Several reports have found that the graveness of criminal charges is correlated with criminal responsibility (Cochrane et al., 2001; Warren, 
Fitch, Dietz, \& Rosenfeld, 1991; Warren, Murrie, Chauhan, Dietz, \& Morris, 2004), and one study about pretrial evaluations stated that the psychiatric diagnoses, rather than the severity of the criminal charges, influenced more on the clinical judgments of responsibility (Cochrane et al., 2001). Warren et al., (2004) also agreed that the defendants' types of diagnosis override the types of offenses in predicting an opinion of insanity. For example, a more serious mental disorder, absence of Axis II diagnosis or substance use, previous psychiatric hospitalizations and not being influenced by drugs at the time of the offense, might have had a more positive relationship with opinions of insanity (Warren et al., 2004). They further explained that the high rates of insanity on certain crime categories could be interpreted as higher rates of psychotic diagnoses being found within them. No significant relationships between the charges and the psycho-legal opinion could be noted once the diagnoses were also considered. Even though we have found three cases with sentences as legal insanity, further research is needed to investigate the relationship among the defendants' psychiatric diagnosis, types of offenses, and criminal responsibility in Taiwan. .

Moreover, many studies had suggested a negative relationship between the substance use and the verdicts or psychological opinions on insanity, reflecting the legal responsibility that derives from voluntary intoxication. However, it may reflect the connotation of wrong-doing and, therefore, culpability in instances wherein substances are paired with criminal behavior (Warren et al., 2004).

One previous studyreported that $57.14 \%$ in the offenders with legal insanity, and $24.59 \%$ with diminished responsibility, were sentenced to receive mandatory psychiatric treatment (W. C. Tsai, H. Rin, \& H. N. Lin, 1996). In this study, only $40 \%$ of the subjects were sentenced to receive mandatory treatment plans. Nielssen et al (2010) found that earlier treatment of first-episode psychosis might prevent some homicides: during the first-episode psychosis, there was an annual rate of 1.59 homicides per 1000 (95\% confidence interval $[\mathrm{Cl}]=1.06-2.40)$, and the annual rate of homicide after treatment for psychosis was 0.11 homicides per 1000 patients $(95 \% \mathrm{Cl}=0.07-0.16)$. (Nielssen \& Large, 2010). However, there is no study for the effectiveness in the mandatory treatment for the homicide defendants with schizophrenia in Taiwan, Since the mandatory treatment for the homicide defendants with schizophrenia has a potential to prevent the rise in future homicide rate, a further study is needed to investigate the after-treatment homicide rate in Taiwan.

There were three cases that had received different professional opinions during repeated evaluations, all were charged with homicides. Limited reports were found about the consistency of professional opinions. One study in Poland found that 68 out of 117 criminal defendants, that had more than one forensic psychiatric evaluation. In addition, the initial criminal responsibility assessment was changed after a subsequent forensic evaluation in $47 \%$ of the cases containing more than one assessments (Kacperska, Heitzman, Bak, Lesko, \& Opio, 2016). There is a clear need for further research for the reliability of repeated forensic psychiatric evaluations in the criminal responsibility assessments.

There are a number of limitations in this study: some demographic information could not be found in the public databank. Gender, exact age (although senility was relatively obvious when reviewing the verdicts), 
level of education, and occupation were not recorded, mostly in the electronic version of verdicts according to the web-based databank's policy. There were also some sentence documents not released due to administrative omission and concerns for protection of privacy or vulnerable groups. The population in this study may not represent all the psychiatric criminal cases, since most insanity determinations were made by the judges and only $33.75 \%$ were accorded with psychiatric evaluations, according to a previous report (Chen \& Chien, 2003).

\section{Conclusions}

Of all the homicide offenders, those who diagnosed with were schizophrenia consisted of a small but significant part. For the schizophrenic criminal offenders, those who committed homicide or attempted homicides had higher rates of court-verdict legal insanity than those with other charges. Homicide cases would be more likely to be regarded as legal insanity or diminished responsibility for the defendants with schizophrenia, in the forensic psychiatric evaluation opinions or the court verdicts.

\section{Declarations}

\section{Ethics approval and consent to participate}

The Institute Review Board of the Tri-Service General Hospital approved this study (No. 2-102-05-044).

\section{Consent for publication}

Not applicable

\section{Availability of data and material}

The datasets used and/or analyzed during the current study are available from the corresponding author on reasonable request.

\section{Competing interests}

The authors declare no conflicts of interest.

\section{Funding}

This work was supported by National Defense Medical Center under Grant MAB-102-69 and the TriService General Hospital Research Foundation (TSGH-C103-102 and TSGH-C104-123).

\section{Authors' contributions}

Hui-Yi Wang was the major contributor in writing the manuscript. Nian-Sheng Tzeng supervised and examined the final result. All authors read and approved the final manuscript. Hsin-An Chang, Yu-Cheng 
Kao, Chin-Bin Yeh, San-Yuan Huang forming data review team. Yu-Ching Chou and Hui-Wen Yeh, doing data analysis. Wei-Shan Chiang and Li-Yao Tang doing online data gathering.

\section{References}

American Psychiatric Association. (2004). Diagnostic and Statistical Manual of Mental Disorders, 4th Edition, Text-Revision (DSM-IV-TR). Washington, DC, USA: American Psychiatric Association.

Arseneault, L., Moffitt, T. E., Caspi, A., Taylor, P. J., \& Silva, P. A. (2000). Mental disorders and violence in a total birth cohort: results from the Dunedin Study. Arch Gen Psychiatry, 57(10), 979-986.

Brennan, P. A., Mednick, S. A., \& Hodgins, S. (2000). Major mental disorders and criminal violence in a Danish birth cohort. Arch Gen Psychiatry, 57(5), 494-500.

Chen, C. C., \& Chien, C. P. (2003). Forensic Psychiatric Assessment in the Determination of Criminal Responsibility in Taiwan. Taiwanese J Psychiatry, 17(3), 215-224.

Chien, W. C., Chung, C. H., Lin, F. H., Chang, H. A., Kao, Y.-C., \& Tzeng, N. S. (2017). Is weight control surgery associated with increased risk of newly onset psychiatric disorders? A population-based, matched cohort study in Taiwan. Journal of Medical Sciences, 37(4), 137-149. doi:10.4103/jmedsci.jmedsci_94_16

Cochrane, R. E., Grisso, T., \& Frederick, R. I. (2001). The relationship between criminal charges, diagnoses, and psycholegal opinions among federal pretrial defendants. Behavioral sciences \& the law, 19(4), 565582.

El-Hadidy, M. A. (2012). Schizophrenia with and without homicide: a clinical comparative study. Journal of Forensic Psychiatry \& Psychology, 23(1), 95-107.

Eronen, M., Tiihonen, J., \& Hakola, P. (1996). Schizophrenia and homicidal behavior. Schizophr Bull, 22(1), 83-89.

Golenkov, A., Large, M., Nielssen, O., \& Tsymbalova, A. (2011). Characteristics of homicide offenders with Schizophrenia from the Russian Federation. Schizophr Res, 133(1-3), 232-237.

doi:10.1016/j.schres.2011.07.008

Golenkov, A., Nielssen, O., \& Large, M. (2014). Systematic review and meta-analysis of homicide recidivism and schizophrenia. BMC psychiatry, 14(1), 46. doi:10.1186/1471-244X-14-46

Ho, H., Tsuang, M. M., Lin, H. N., \& Rin, H. (1997). Results of forensic psychiatric evaluation and the court sentencing. Taiwanese J Psychiatry, 11, 262-268 (in Traditional Chinese with English Abstract).

Ho, L. C. J., Wu, A., \& Huang, C. J. (2010). An Empirical Investigation of the Parole Policy in Taiwan. Journal of Social Sciences and Philosophy, 22(1), 109-138 doi:10.6350/JSSP.201003.0109 
Joyal, C. C., Putkonen, A., Paavola, P., \& Tiihonen, J. (2004). Characteristics and circumstances of homicidal acts committed by offenders with schizophrenia. Psychol Med, 34(3), 433-442.

Kacperska, I., Heitzman, J., Bak, T., Lesko, A. W., \& Opio, M. (2016). Reliability of repeated forensic evaluations of legal sanity. Int J Law Psychiatry, 44, 24-29. doi:10.1016/j.ijlp.2015.08.028

Kuo, S. H. (1983). Forensic psychiatry in Taiwan. Int J Law Psychiatry, 6(3-4), 457-472.

Large, M., Smith, G., \& Nielssen, O. (2009). The relationship between the rate of homicide by those with schizophrenia and the overall homicide rate: a systematic review and meta-analysis. Schizophrenia research, 112(1), 123-129. doi:10.1016/j.schres.2009.04.004

Meehan, J., Flynn, S., Hunt, I. M., Robinson, J., Bickley, H., Parsons, R., . . Shaw, J. (2006). Perpetrators of homicide with schizophrenia: a national clinical survey in England and Wales. Psychiatr Serv, 57(11), 1648-1651. doi:10.1176/appi.ps.57.11.1648

Mullen, P. E., Burgess, P., Wallace, C., Palmer, S., \& Ruschena, D. (2000). Community care and criminal offending in schizophrenia. Lancet, 355(9204), 614-617. doi:10.1016/S0140-6736(99)05082-5

Nicholson, R. A., \& Kugler, K. E. (1991). Competent and incompetent criminal defendants: a quantitative review of comparative research. Psychol Bull, 109(3), 355-370.

Nielssen, O., \& Large, M. (2010). Rates of homicide during the first episode of psychosis and after treatment: a systematic review and meta-analysis. Schizophr Bull, 36(4), 702-712. doi:10.1093/schbul/sbn144

Packer, I. K. (1987). Homicide and the insanity defense: A comparison of sane and insane murderers. Behavioral sciences \& the law, 5(1), 25-35.

Rin, H. (1976). Psychopathological study on criminal responsibility of mentally ill offenders. Taiwan Yi Xue Hui Za Zhi (Journal of the Formosan Medical Association), 75(03), 175-182.

Rosenfeld, B., \& Ritchie, K. (1998). Competence to stand trial: clinician reliability and the role of offense severity. J Forensic Sci, 43(1), 151-157.

Schanda, H., Knecht, G., Schreinzer, D., Stompe, T., Ortwein-Swoboda, G., \& Waldhoer, T. (2004). Homicide and major mental disorders: a 25-year study. Acta Psychiatr Scand, 110(2), 98-107. doi:10.1111/j.16000047.2004.00305.x

Steadman, H. J., \& Hartstone, E. (1983). Defendants incompetent to stand trial. In Mentally disordered offenders (pp. 39-62): Springer.

Su, K. P., Yu, J. M., Yang, T. W., Tsai, S. Y., \& Chen, C. C., . (2000). Characteristics of mentally retarded criminal offenders in Northern Taiwan. J Forensic Sci, 45(6), 1207-1209. 
Tsai, W. C., Rin, H., \& Lin, H. N. (1996). Trend of Forensic Psychiatric Examination on Criminal Offenders in Taiwan. Taiwanese J Psychiatry, 10, 243-250.

Tsai, W. C., Rin, H., \& Lin, S. N. (1996). Trend of Forensic Psychiatric Examination in criminal offenders in Taiwan. Taiwanese J Psychiatry, 10, 243-250.

Tzeng, N. S., Chen, C. K., Wang, T. S., Chang, H. A., Kao, Y. C., Yeh, H. W., . . Huang, S. Y. (2016). Forensic Psychiatric Evaluation for Military Absenteeism in Taiwan. J Am Acad Psychiatry Law, 44(3), 352-358.

Wang, H. Y., Chen, J. H., Huang, S. Y., Yeh, H. W., Mao, W. C., Chang, H. A., . . Tzeng, N. S. (2018). Forensic Evaluations for Offenders With Dementia in Taiwan's Criminal Courts. J Am Acad Psychiatry Law, 46(1), 45-51.

Warren, J. I., Fitch, W. L., Dietz, P. E., \& Rosenfeld, B. D. (1991). Criminal offense, psychiatric diagnosis, and psycholegal opinion: an analysis of 894 pretrial referrals. Bull Am Acad Psychiatry Law, 19(1), 63-69.

Warren, J. I., Murrie, D. C., Chauhan, P., Dietz, P. E., \& Morris, J. (2004). Opinion formation in evaluating sanity at the time of the offense: An examination of 5175 pre-trial evaluations. Behavioral sciences \& the law, 22(2), 171-186.

Warren, J. I., Rosenfeld, B., Fitch, W. L., \& Hawk, G. (1997). Forensic mental health clinical evaluation: an analysis of interstate and intersystemic differences. Law Hum Behav, 21(4), 377-390. doi:10.1023/A:1024855118855

Wu, P. C., Chou, Y. C., Yeh, H. W., Huang, S. Y., Cheng, L. H., Kao, Y. C., . . Tzeng, N. S. (2017). Offenders With Substance Abuse Who Receive Mandatory Psychiatric Treatment. J Am Acad Psychiatry Law, 45(3), 316-324.

Yang, S. L., Tsai, T. H., \& Jang, B. H. (2008). Constrcution of Susbtance Abusers Treatment and Management Models for the Inmates in Correctional Institues: A Report for Ministry of Justice. Retrieved from http://refrain.moj.gov.tw/public/Data/13112153571.pdf

Yang, T. W., Yu, J. M., \& Pan, C. H. (2017). Analysis of concordance between conclusions of forensic psychiatric evaluation and court decisions after 2005 Criminal Code Amendment in a Taiwan psychiatric hospital. Int J Law Psychiatry, 54, 148-154. doi:10.1016/j.jilp.2017.06.010

Yeh, T. C., Chou, Y. C., Weng, J. P., Yeh, H. W., Kao, Y. C., Chiang, W. S., .. Tzeng, N. S. (2019). Detection of malingering in the memory of patients with dementia: A pilot study on coin-in-the-hand test in a Northern Taiwan Memory Clinic. Journal of Medical Sciences, 39(2), 81-89. doi:10.4103/jmedsci.jmedsci_100_18

Yu, J. M., Yang, T. W., Chou, J. Y., Hsu, H. W., Lu, H. H., Chen, C. C., \& Hu, W. H. (2005). Analysis of Discordance between Conclusions of Forensic Psychiatric Evaluation and Court Decisions (I): Mental Status at the Time of Offense. Taiwanese J Psychiatry, 19(3), 225-236. 


\section{Tables}

Table 1. Characteristics between offenders with schizophrenia in homicide and non-homicide groups 


\begin{tabular}{|c|c|c|c|c|}
\hline & & $\begin{array}{l}\text { Homicides } \\
\qquad(n=33)\end{array}$ & $\begin{array}{l}\text { Non-homicide } \\
\qquad(n=22)\end{array}$ & $\begin{array}{c}\mathrm{a}_{P} \\
\text { value }\end{array}$ \\
\hline & & n (\%) & n (\%) & \\
\hline \multirow[t]{2}{*}{ Sex } & Male & $31(93.94)$ & $20(90.91)$ & 1.000 \\
\hline & Female & $2(6.06)$ & $2(9.09)$ & \\
\hline \multirow[t]{4}{*}{ Types of offense } & Homicide & $24(72.73)$ & -- & - \\
\hline & Attempted homicide & $9(27.27)$ & -- & \\
\hline & Felony & -- & $20(90.91)$ & \\
\hline & Not felony & -- & $2(9.09)$ & \\
\hline \multirow[t]{6}{*}{ Comorbidity } & N/A & $21(63.64)$ & $17(77.27)$ & 0.900 \\
\hline & Substance use disorder & $6(18.18)$ & $4(18.18)$ & \\
\hline & Organic mental disorder & $2(6.06)$ & $1(4.55)$ & \\
\hline & Personality disorder & $2(6.06)$ & $0(0)$ & \\
\hline & $\begin{array}{l}\text { Substance use disorder + organic mental } \\
\text { disorder }\end{array}$ & $1(3.03)$ & $0(0)$ & \\
\hline & $\begin{array}{l}\text { Substance use disorder + personality } \\
\text { disorder }\end{array}$ & $1(3.03)$ & $0(0)$ & \\
\hline \multirow[t]{4}{*}{ Responsibility } & & & & $0.029 *$ \\
\hline & No responsibility (legal insanity) & $3(9.09)$ & $0(0)$ & \\
\hline & Diminished responsibility & $21(63.64)$ & $9(40.91)$ & \\
\hline & Full responsibility & $9(27.27)$ & $13(59.09)$ & \\
\hline \multirow{5}{*}{$\begin{array}{l}\text { Professional } \\
\text { opinion }\end{array}$} & & & & 0.197 \\
\hline & No responsibility (legal insanity) & $3(9.09)$ & $1(4.55)$ & \\
\hline & Diminished responsibility & $20(60.61)$ & $11(50.00)$ & \\
\hline & Full responsibility & $7(21.21)$ & $10(45.45)$ & \\
\hline & Inconsistent & $3(9.09)$ & $3(0)$ & \\
\hline
\end{tabular}


ratet

Times of

evaluation

\begin{tabular}{|c|c|c|c|c|}
\hline & Single & $24(72.73)$ & $20(90.91)$ & \\
\hline & Multiple ( $\geqq 2$ evaluations) & $9(27.27)$ & $2(9.09)$ & \\
\hline Mandatory & & & & $0.014^{*}$ \\
\hline \multicolumn{5}{|l|}{ treatment } \\
\hline & No & $15(45.45)$ & $18(81.82)$ & \\
\hline & Yes & $16(48.48)$ & $4(18.18)$ & \\
\hline & Not mentioned & $2(6.06)$ & $0(0)$ & \\
\hline \multicolumn{5}{|c|}{ Organization ${ }^{\ddagger}$} \\
\hline & Medical center & $15(32.61)$ & $5(20.83)$ & 0.576 \\
\hline & Regional hospital & $28(60.87)$ & $18(75.00)$ & \\
\hline & Local hospital & $3(6.52)$ & $1(4.17)$ & \\
\hline
\end{tabular}

${ }^{\mathrm{a}}$ Chi-square test or Fisher's exact test; ${ }^{*} p<0.05 ; * * p<0.01, * * *<<0.001$; + Concordance between the last psychiatric opinions and the court verdicts; $¥$ Some cases receive multiple evaluations in different levels of hospitals

Table 2. Difference between homicide and attempted homicide groups 


\begin{tabular}{|c|c|c|c|c|}
\hline & & $\begin{array}{l}\text { Homicides } \\
\qquad(\mathrm{n}=24)\end{array}$ & $\begin{array}{l}\text { Attempted homicides } \\
\qquad(\mathrm{n}=9)\end{array}$ & $\begin{array}{l}\mathrm{a}_{\mathrm{P}} \\
\text { value }\end{array}$ \\
\hline & & n (\%) & n (\%) & \\
\hline \multirow[t]{2}{*}{ Sex } & Male & $23(95.83)$ & $8(88.89)$ & 0.477 \\
\hline & Female & $1(4.17)$ & $1(11.11)$ & \\
\hline \multirow[t]{6}{*}{ Comorbidity } & N/A & $15(62.50)$ & $6(66.67)$ & 0.798 \\
\hline & Substance & $5(20.83)$ & $1(11.11)$ & \\
\hline & Organicity mental disorder & $1(4.17)$ & $1(11.11)$ & \\
\hline & Personality disorder & $1(4.17)$ & $1(11.11)$ & \\
\hline & $\begin{array}{l}\text { Substance use disorder }+ \text { organic } \\
\text { mental disorder }\end{array}$ & $1(4.17)$ & $1(11.11)$ & \\
\hline & $\begin{array}{l}\text { Substance use disorder + personality } \\
\text { disorder }\end{array}$ & $1(4.17)$ & $0(0)$ & \\
\hline \multirow[t]{4}{*}{ Responsibility } & & & & 0.065 \\
\hline & No responsibility (legal insanity) & $2(8.33)$ & $1(11.11)$ & \\
\hline & Diminished responsibility & $18(75.00)$ & $3(33.33)$ & \\
\hline & Full responsibility & $4(16.67)$ & $5(55.56)$ & \\
\hline \multirow{6}{*}{$\begin{array}{l}\text { Professional } \\
\text { opinion }\end{array}$} & & & & 0.734 \\
\hline & & & & \\
\hline & No responsibility (legal insanity) & $2(8.33)$ & $1(11.11)$ & \\
\hline & Diminished responsibility & $15(62.50)$ & $5(55.56)$ & \\
\hline & Full responsibility & $4(16.67)$ & $3(33.33)$ & \\
\hline & Not consistent & $3(12.50)$ & $0(0)$ & \\
\hline $\begin{array}{l}\text { Concordance } \\
\text { rate }^{\dagger}\end{array}$ & & $24(100.00)$ & $7(77.78)$ & 0.068 \\
\hline \multirow[t]{2}{*}{$\begin{array}{l}\text { Times } \\
\text { evaluation }\end{array}$} & & & & 0.384 \\
\hline & Single & $16(66.67)$ & $8(88.89)$ & \\
\hline
\end{tabular}



Multiple ( $\geqq 2$ evaluations)
8 (33.33)
$1(11.11)$

Mandatory

0.290

treatment

\begin{tabular}{llcc}
\hline No & $9(37.50)$ & $6(66.67)$ \\
\hline Yes & $13(54.17)$ & $3(33.33)$ \\
& Not Mentioned & $2(8.33)$ & $0(0)$ \\
\hline Organizations $^{\ddagger}$ & & $\mathrm{n}=36$ & $\mathrm{n}=10$ \\
\hline & Medical center & $14(38.89)$ & $1(10.00)$ \\
\hline \\
\hline
\end{tabular}

${ }^{\mathrm{a}}$ Chi-square test or Fisher's exact test; * $p<0.05 ; * * p<0.01, * * *<0.001 ;+$ Concordance between the last psychiatric opinions and the court verdicts; $¥$ Some cases receive multiple evaluations in different levels of hospitals

Table 3. Difference between offenders with homicides who received one or more than one evaluation 


\begin{tabular}{|c|c|c|c|c|}
\hline & & $\begin{array}{l}\text { Single evaluations } \\
\qquad(\mathrm{n}=24)\end{array}$ & $\begin{array}{c}\text { Multiple } \\
\text { evaluations }(n=9)\end{array}$ & $a_{P}$ value \\
\hline & & $\mathrm{n}(\%)$ & $\mathrm{n}(\%)$ & \\
\hline \multirow[t]{2}{*}{ Sex } & Male & $23(95.83)$ & $8(88.89)$ & 0.477 \\
\hline & Female & $1(4.17)$ & $1(11.11)$ & \\
\hline \multirow[t]{8}{*}{ Comorbidity } & $\mathrm{N} / \mathrm{A}$ & $16(66.67)$ & $5(55.56)$ & 0.246 \\
\hline & Substance & $5(20.83)$ & $1(11.11)$ & \\
\hline & Organicity mental disorder & $1(4.17)$ & $1(11.11)$ & \\
\hline & Personality disorder & $2(8.33)$ & $0(0)$ & \\
\hline & Substance use disorder + organic & $0(0)$ & $1(11.11)$ & \\
\hline & mental disorder & & & \\
\hline & Substance use disorder + & $0(0)$ & $1(11.11)$ & \\
\hline & personality disorder & & & \\
\hline \multirow[t]{4}{*}{ Responsibility } & & & & $0.017^{*}$ \\
\hline & No responsibility (legal insanity) & $0(0)$ & $3(33.33)$ & \\
\hline & Diminished responsibility & $16(66.67)$ & $5(55.56)$ & \\
\hline & Full responsibility & $8(33.33)$ & $1(11.11)$ & \\
\hline \multirow{5}{*}{$\begin{array}{l}\text { Professional } \\
\text { opinion }\end{array}$} & & & & $<0.001^{\star * \star}$ \\
\hline & No responsibility (legal insanity) & $0(0)$ & $3(33.33)$ & \\
\hline & Diminished responsibility & $18(75.00)$ & $2(22.22)$ & \\
\hline & Full responsibility & $6(25.00)$ & $1(11.11)$ & \\
\hline & Inconsistent & $0(0)$ & 3 (33.33) & \\
\hline Concordance & & $22(91.67)$ & $9(100.00)$ & 1.000 \\
\hline rate $^{\dagger}$ & & & & \\
\hline \multirow[t]{3}{*}{ Types of } & & & & 0.391 \\
\hline & & & & \\
\hline & Homicide & $18(69.23)$ & 8 (88.89) & \\
\hline
\end{tabular}


treatment

\begin{tabular}{clccc}
\hline No & $11(45.83)$ & $4(44.44)$ \\
\hline & Yes & $11(45.83)$ & $5(55.56)$ & \\
\hline & No but mentioned & $2(8.33)$ & $0(0)$ & 0.232 \\
\hline Organizations $^{\ddagger}$ & & & & \\
\cline { 2 - 4 } & Medical center & $5(20.83)$ & $10(45.45)$ & \\
\hline & Regional hospital & $17(70.83)$ & $11(50.00)$ \\
\hline & Local hospital & $2(8.33)$ & $1(4.55)$ \\
\hline
\end{tabular}

${ }^{a}$ Chi-square test or Fisher's exact test; ${ }^{*} p<0.05 ; * \star p<0.01, * \star * p<0.001 ;+$ Concordance between the last psychiatric opinions and the court verdicts; ¥Some cases receive multiple evaluations in different levels of hospitals 